\title{
India's progress in implementing the UN Convention on the Rights of Persons with Disabilities
}

Edition 6, 2021

Professor Paul Chaney

DOI: 10.37839/MAR2652-550X6.12

Official data tell us there are currently 27 million persons with disabilities in India. In 2008, the country was swift to sign and ratify the United Nations Convention on the Rights of Persons with Disabilities-the first comprehensive human rights treaty of the 21st century, aiming to 'take to a new height the movement from viewing persons with disabilities as 'objects' of charity, medical treatment and social protection towards viewing persons with disabilities as 'subjects' with rights, who are capable of claiming those rights and making decisions for their lives based on their free and informed consent as well as being active members of society'.

The Convention has an explicit social development dimension that reaffirms that all Persons with Disabilities must enjoy all human rights and fundamental freedoms. Whilst India's swift adoption of the Convention appeared to bode well, a recent United Nations' assessment suggests that implementation has proved problematic. It notes ongoing concern at: 'legislation, public policies and practices that discriminate against persons with disabilities - in particular: guardianship, institutionalisation, psychiatric treatment and segregated community services based on disability, and negative perceptions'.

These concerns resonate with ongoing research on citizenship rights in India and prompted my benchmark study that analyses civil society views on the impact of the Convention, more than a decade after India's ratification. 


\section{What did we previously know about disability in India?}

The official 27 million Persons with Disabilities in India is likely an underestimation given narrow categories and definitions of disability. The expanded definition in the latest Act will mean that in the next census this figure will be much higher. The figure will also rise because of demographic factors; specifically, an ageing population and the growing prevalence of multiple disabilities among older people in India. The 2011 Census gives an idea of the scale of the future policy-challenge that this presents. It revealed that the number of people aged over 60 years had reached 103.8 million, with 11.3 million aged over 80 . Forecasts suggest a further significant demographic shift-that by 2050 there will be 323 million people over the age of 60 . This has major implications for the future number of people with disabilities requiring health and social care, as well issues of rights, empowerment, independence, equality, and other aspects of social welfare covered by the Convention.

Earlier research has highlighted widespread prejudice towards Persons with Disabilities. A range of studies conclude that cultural and religious beliefs underpin negative attitudes towards disability, leading to widespread attitudinal barriers. As independent litigation lawyer Tushti Chopra has observed: Persons with Disabilities 'are not considered a basic unit of society. Infanticide of disabled persons is not uncommon in India. Society sometimes looks down and ostracises them to avoid incurring any liability towards them, since they are considered to be suffering for their previous birth deeds. In addition, there is a gendered dimension to this discrimination: Academic and former president of the Indian Association of Women's Studies Anita Ghai has highlighted how the rise of neoliberalism in India has exacerbated the oppression and exclusion faced by disabled women. She notes this is confirmed by statistical analysis showing that disabled women are marginalised much more than disabled men. 


\section{Why explore civil society perspectives on the rights of persons with disabilities in India?}

Three main reasons underpin the decision to explore civil society views on the implementation of the Convention on the Rights of Persons with Disabilities.

First, it complements 'official accounts' often written by bureaucrats using secondary data. In social theory terms, it has the potential to offer greater insight based on the situated knowledge of civil society organisations run by and for persons with disabilities and/or other protected characteristics. (The focus is civil society organisations submitting to the third cycle of the Universal Periodic Review, the five yearly monitoring programme of human rights compliance for all counties overseen by the United Nations. Some are Disabled People's Organisations, others are concerned with other protected characteristics and/or the generic promotion of equality and human rights.) In other words, the views and experiences of people who have everyday knowledge of the situation facing persons with disabilities.

Second, the participation of persons with disabilities in civil society is written into the Convention. The Preamble requires governments to 'promote their participation in the civil, political, economic, social and cultural spheres with equal opportunities, in both developing and developed countries'. Article 32 goes on to say that signatory states, including India, 'will undertake appropriate and effective measures... in partnership with relevant international and regional organizations and civil society, in particular organizations of persons with disabilities' (emphasis added).

The third reason is that civil society organisations' reports are a required part of the Universal Periodic Review. 


\section{Research methodology}

In methodological terms, the current approach offers a transferable discourse-based technique for studying rights implementation. It has two parts: the first centres on understanding the key Convention implementation issues across public policy areas as identified by CSOs, and the second explores CSOs' use of language in their UPR submissions.

The dataset used in this study is derived from state and civil society submissions to the UPR. It is a singular, rich source that advances understanding of the role of civil society as a political space for resistance to oppression and the realisation of the rights of Persons with Disabilities. The UPR emerged in the wake of the 2006 UN General Assembly resolution (60/251) and is conducted under the auspices of the Office of the High Commissioner on Human Rights. Its proponents argue that it provides the opportunity for each state to outline the actions they have undertaken in order to promote human rights. To do this it makes provision for civil society input. The policy guidance is unambiguous: 'the UPR should ensure the participation of all relevant stakeholders, including non-governmental organizations'.

The present use of discourse analysis is underpinned by diverse strands of social theory, including the interpretive school of policy analysis and social constructivism. Both place emphasis on values, beliefs and interpretations relevant to a given policy issue. The epistemological grounding of the present research is standpoint theory. In particular, the notion of situated knowledge. This states that first-hand accounts (in this case, from organisations representing Persons with Disabilities affected by oppression and discrimination) are a valuable complement to records of jurisprudence and institutional proceedings.

The data for the present study are drawn from a rigorous content analysis of 72 civil society organisations' reports submitted to the third UN UPR in 2017 (and covering the preceding five years). The aforementioned number of civil society organisations' submissions under-reports the breadth of civil society input, because many are joint 
submissions authored by broad coalitions of standalone organisations (one, for example, is made up of 181 CSOs). The length of the reports varies. The 26 submissions from single civil society organisations were typically 2,000 words in length (e.g., Access Now). Whilst the 46 joint submissions from alliances and networks were typically 15,000 words, those with Annexes were up to 30,000 words in length. Overall, the corpus of civil society organisations' UPR submissions is a rich data source that totals 750,000 words.

More details on the methodology employed can be found in the full study.

\section{What did the study find about the contemporary situation of persons with a disability in India?}

The headline finding is that Persons with Disabilities continue to experience rightsdenial and institutional ableism. The latter term refers to the situation when social groups and social structures promote certain abilities over others. In short, this form of discrimination is based on the perception that being able-bodied is the 'normal' human condition and is superior to being disabled.

Institutional ableism denies the human rights of Persons with Disabilities throughout the public policy-making process and reflects the failure of successive post-2007 governments in India to put in place a comprehensive strategy for implementing the Convention. This is indicative of an ongoing disjuncture between the priorities and actions of the Indian Government compared to those of civil society organisations. Yet, progressive measures such as The Rights of Persons with Disabilities Act (2016) should be acknowledged, as should the advent of the Department of Empowerment of Persons with Disabilities (Divyangjan).

My study examined the implementation of the Convention in light of such developments and across a breadth of policy areas. In relation to education, for 
example, since ratification of the Convention in 2008, the Indian government and its agencies have been subject to Article 24:

'States Parties [i.e. the Indian Government] recognize the right of persons with disabilities to education. With a view to realizing this right without discrimination and on the basis of equal opportunity, States Parties shall ensure an inclusive education system at all levels and lifelong learning directed to:

(a) The full development of human potential and sense of dignity and self-worth, and the strengthening of respect for human rights, fundamental freedoms and human diversity;

(b) The development by persons with disabilities of their personality, talents and creativity, as well as their mental and physical abilities, to their fullest potential.'

However, my research shows rights violations in education are the first-ranked policy issue in civil society organisations' submissions to the Universal Periodic Review, accounting for almost a third of all civil society organisations' discourse in their reports to the United Nations.

Civil society organisations' submissions reveal little progress on education since the second-cycle UPR in 2012. The discourse points to many reasons for this, including a lack of political will to address rights violations and a failure to uphold the law.

A core theme in the civil society discourse was a general failure to comply with India's Right of Children to Free and Compulsory Education Act (2009). Amongst the issues highlighted was the fact that specific educational services for children with disabilities continue to be unavailable to the majority, and that budgetary allocations for educational programmes related to children with disabilities are poorly funded and unable to cater the needs of such children.

Additionally, the discourse revealed how private schools are largely ignoring the minimum standards set out in the 2009 Act; including the provision of a trained 
teacher, improvements in physical access to school premises, and delivering a minimum number of instructional hours each year.

In terms of language use, the study reveals how civil society organisations' critical discourse emphasises the need for India to move away from the outdated Medical Model and embrace the Social Model of Disability. The Medical Model regards the disabled person as the problem. Typically, attention centres on impairment and there is a discourse of cures, 'normalisation' and science. In contrast, the Convention is predicated on the Social Model of Disability. This explains disability as a function of the inequalities and discrimination that prevent persons with disabilities fully taking part in the life of society, including education.

The dominant themes emerging from the present discourse analysis of the submissions by civil society organisations to the UN include:

- The violation of the rights of Persons with Disabilities,

- Discrimination against Persons with Disabilities,

- Denial of participation of Persons with Disabilities in formal decisionmaking,

- The exploitation of Persons with Disabilities,

- A lack of access to public services; and

- Independence/ending the detention of People with Disabilities in institutions.

\section{How do the study findings amount to institutional ableism?}

The study findings reflect the situation when social groups and social structures promote certain abilities over others. In short, this form of discrimination is based on the perception that being able-bodied is the 'normal' human condition and is superior to being disabled. Moreover, it is shown to be systemic. That is, it pervades the wider state and public sector system. It can be detected in processes, attitudes 
and behaviour that amount to discrimination against disabled persons through prejudice, ignorance, thoughtlessness, and ableist stereotyping which disadvantages Persons with Disabilities.

This study found that it pervaded the breadth of public services and welfare provision, including:

- Education - The civil society discourse found that despite the enactment of the law on rights to education, discrimination (particularly discrimination that affects girls, marginal groups, and Persons with Disability) continues. Inadequate number of teachers, teacher absenteeism and poor-quality teaching and learning remain.

- Law and the Administration of Justice - The civil society discourse called for a more progressive anti-discrimination law to address all types of discrimination that would be enforceable against private enterprises and transnational actors. Further calls were for an amendment to the Disabilities Act to protect women and girls with intellectual disabilities from forced sterilisation.

- Intersectionality - Much of the civil society discourse is critical of government's tendency to overlook disabled people's multiple identities. Particular attention is given to Article 6 violations and how women face multiple layers of discrimination with regard to access, control, ownership, and inheritance of land, property, and housing. According to one CSO, 'the worst marginalization is experienced by women who are living with mental illness, HIV/AIDS, [and] disability'.

- Employment/socio-economic inequalities - For all age groups, the civil society discourse points to widespread and systemic barriers to employment for persons with disabilities operating over the life-course, as well as how this is linked to education. A key concern in the UPR submissions was how children with disabilities in rural areas are often excluded from the education system due to physical and/or social barriers. As a consequence, many receive no education at all. For those that do manage to attend, civil 
society organisations also highlighted high drop-out rates and alluded to how the lack of motivation and encouragement to attend school leads to increasing unemployment and poverty for disabled people. For example, one CSO observed that 'the employment rate both in terms of wages and selfemployment is less than $10 \%$ for persons with disabilities due to negative attitudes, inaccessibility and unaffordability of technology and transport systems'.

- Health - The discourse shows how CSOs feel there has been little progress since the second cycle UPR. At that time, writing about policies and services for persons with intellectual disability, academic analysis underlined the prevalence of the Medical Model of Disability in healthcare. Amongst the myriad issues highlighted was states' failure to comply with their constitutional duty to all citizens, including persons with disability, to raise the level of nutrition, healthcare and standard of living. A further core concern was authorities' failure to make healthcare more accessible to disabled people.

- Housing - Almost a decade ago, the UN recommended that the Indian Government, 'ensure better protection for persons with disabilities'. Yet the most recent civil society data reveal how access to housing and basic services is still a struggle for Persons with Disabilities. The civil society discourse notes that whilst several housing schemes contain provisions for Persons with Disabilities, including preferential allocation, these are dwarfed by the actual scale of demand. Others alluded to tensions between the state's human rights obligations and neo-liberal approaches to the economy. One civil society organisation complained that India's macroeconomic growth paradigm promotes homelessness, forced evictions, land grabbing/alienation, and displacement. It noted that, 'in the last four years, several cases of violations of housing and land rights have been reported across the country; the worst affected include persons with disabilities'. 


\section{Why do these findings matter?}

- They show the existence of institutional ableism in today's India; and

- They underline that contemporary thinking about disability largely remains rooted in the Medical Model of disability, instead of embracing a more sophisticated, Social Model view of the rights of persons with disabilities as social, cultural and political phenomena.

The United Nations concurs, noting amongst its principal concerns that the 'prevalence of the Medical Model of disability in legislation, public policies and attitudes concerning persons with disabilities... and in the misunderstanding of disability, including leprosy, as solely a biological condition requiring prevention and rehabilitation.'

Future progress in implementing the Convention on the Rights of Persons with Disabilities will require multi-dimensional action to tackle institutional ableism and move away from the Medical Model. At present, future progress in implementing the Convention looks uncertain, and millions of persons with disability will continue to face discrimination, oppression and rights denial.

For full details of the study, see Chaney, P. (2020) An Institutionally Ableist State? Exploring Civil Society Perspectives on the Implementation of the Convention on the Rights of Persons with Disabilities in India, Journal of Civil Society, Routledge T\&F (C) CC-BY licence - Open Access. DOI: 10.1080/17448689.2020.1852824

This research was undertaken as part of: Trust, human rights and civil society within mixed economies of welfare | WISERD in WISERD's Civil Society Research Programme.

Image: A man in India using a three-wheeled vehicle. Credit: Community Eye Health/Flickr.

'Civil Society and Citizenship in India and Bangladesh' 


\section{MELBOURNE ASIA REVIEW}

May 10, 2021

Sarbeswar Sahoo (Volume Editor), Paul Chaney (Volume Editor) 